\title{
ESTILOS DE AGRICULTURA E ESTRATÉGIAS DE REPRODUÇÃO SOCIAL NO ASSENTAMENTO CONQUISTA DA ESPERANÇA, MUNICÍPIO DE TUPANCIRETÃ/RS 1
}

\section{FARMING STYLES AND REPRODUCTIVE STRATEGIES IN SOCIAL SETTLEMENT OF HOPE CONQUEST, MUNICIPALITY OF TUPANCIRETÃ / RS}

\author{
Alisson Vicente Zarnott \\ Universidade Federal de Santa Maria - Santa Maria - RS - Brasil \\ Eduardo Miotto Flech \\ Universidade Federal de Santa Maria - Santa Maria - RS - Brasil \\ Pedro Selvino Neumann \\ Universidade Federal de Santa Maria - Santa Maria - RS - Brasil
}

\begin{abstract}
Resumo: O presente trabalho tem por objetivo investigar as estratégias de reprodução social e os estilos de agricultura desenvolvidos no assentamento Conquista da Esperança no Município de Tupanciretã-RS. A pesquisa segue a abordagem da Perspectiva Orientadaao Ator-POA e foi realizada por meio de uma abordagem quantitativa em que 13 famílias do assentamento foram entrevistadas com auxílio de um formulário em 2013 e depois, em 2015, foram utilizados dados do Sistema Integrado de Gestão Rural-SIGRA, do Programa de Assessoria Técnica, Social e Ambiental-ATES para assentamentos de reforma agrária. Os dados foram analisados através do software SPSS. Os resultados mostram a existência de uma diversidade de estratégias (re)produtivas em curso, como a atividade leiteira, a sojicultura, a pluriatividade, a bovinocultura de corte, a horticultura, a produção para o autoconsumo, entre outras, e que o trinômio leite/soja/atividade não agrícola é a estratégia de reprodução mais adotada. Percebe-se também que as famílias assentadas manejam suas atividades produtivas de acordo com a disponibilidade de força de trabalho, de recursos financeiros, da variação de preços e da existência de políticas de apoio à produção e comercialização. Conclui-se também que, em que pese
\end{abstract}

\footnotetext{
1 O presente artigo baseia-se emparte no trabalho final elaborado para a disciplina de
} Métodos Quantitativos do PPGExR/UFSM. 
a pressão exercida pelo agronegócio no entorno do assentamento Conquista da Esperança, as famílias assentadas confirmam a tendência da agricultura familiar de desenvolver respostas individuais e construir uma diversidade de estratégias reprodutivas diferindo da agricultura patronal predominante no município e caracterizada pelo cultivo isolado de soja.

Palavras-chave: Perspectiva Orientada ao Ator (POA). Reforma Agrária. Diversidade.

Abstract: This study aims to investigate the social reproduction strategies and styles of farming developed in Conquista da Esperança settlement in the municipality of Tupanciretã/RS. The research follows a Approach Perspective Actor (APA) and was conducted through a quantitative approach where 13 families of the settlement were interviewed with the aid of a form in 2013 and then in 2015, we used data of the System Integrated Rural Management of the Technical Assistance, Social and Environmental program for agrarian reform settlements. Data were analyzed using SPSS software. The results show the existence of a variety of strategies (re) production in progress as dairy farming, soy production, pluriactivity, beef cattle to, horticulture, production for self, among others and the trinomial milk / soy / non-agricultural activity is the most adopted reproduction strategy. It is also perceived that the resettled families handle their productive activities according to the availability of manpower, financial resources, the price change and the existence of supporting the production and marketing policies. Also concluded that, despite the pressure from the agribusiness surrounding the settlement of Conquista da Esperança, the families settled confirm the trend of family farming to develop individual responses and build a diversity of reproductive strategies differ from the prevailing commercial farmers in the municipality and characterized by isolated soybean cultivation.

Keywords: Oriented Perspective to Actor (POA). Land reform. Diversity.

\section{Introdução}

Nas últimas décadas, está em curso um processo de (re)valorização da agricultura familiar, categoria social que nas décadas de 1960/1970 esteve condenada pelas ciências sociais ao desaparecimento. Esse processo de (re)afirmação ocorreu concomitantemente à busca por um conceito capaz de sintetizar suas características definidoras. Paralelamente, mas não em contradição, a afirmação de um conceito geral para a agricultura familiar foi acompanhado pela verificação de uma grande diversidade de realidades e arranjos dessas características (SCHNEIDER, 2006).

Essa diversidade é derivada de diferentes estratégias de reprodução social adotadas pelos agricultores familiares. E essas estão, por sua vez, relacionadas com fatores ligados à dinâmica global e regional, como as formas de ocupação do território, de acesso à terra e 
às diferenças culturais e a aspectos relativos a unidade familiar, como seus valores, crenças e os modos de organização do trabalho e da produção (CONTERATO, 2008; CONTERATO, SCHNEIDER e WAQUIL, 2010; CONTERATO et al., 2011; COTRIM, 2003; COTRIM 2007; NIEDERLE, 2007; SCHNEIDER, 2010; SCHNEIDER e NIDERLE, 2008).

Os fatores globais têm influenciado sobremaneira a agricultura familiar. O momento atual pela qual passa a agricultura capitalista globalizada tem exercido grande pressão sobre a agricultura familiar, resultando em um processo de "sojicização da agricultura familiar" (CONTERATO, 2004). Por outro lado, a globalização também tem levado a uma (re)valorização do local por meio da (re)valorização de cultivos, práticas, culturas e do saber-fazer da agricultura familiar (CERDAN, 2009; PECQUER, 2009; FROEHLICH, 1998, 2011; NIEDERLE, 2013), mantendo, e até mesmo recuperando, a diversidade da produção da agricultura familiar.

Nesse cenário, a abordagem dos estilos de agricultura se mostra adequada para o estudo das estratégias de reprodução social da agricultura familiar de um determinado território. Isso pode ser afirmado uma vez que esse referencial enfatiza a lógica produtiva e social das unidades familiares não - de forma fatalista - como mera reprodução dos sistemas dominantes na região, mas como desdobramento da capacidade de agência das famílias que, considerando o ambiente em que estão inseridas, seu conjunto de normas, valores, noções, percepções, práticas e suas inter-relações específicas com os mercados, organizam suas Unidades de Produção Agrícola-UPA.

Segundo Ploeg (1994, p.17), os diferentes estilos de agricultura referem-se às dimensões da cultura e da localidade procurando representar "um complexo e integrado conjunto de noções, normas, conhecimentos, experiências, etc., portados por um grupo de agricultores em uma região específica, que descreve o modo com que a práxis agrícola é levada adiante".

Dessa forma, é central para a análise dos estilos de agricultura considerar a capacidade de agência dos atores e, para tanto, utiliza-se como referencial teórico a POA. Segundo Deponti (2007), a POA referese a uma abordagem teórica e metodológica que permite o estudo da ação social, abrindo espaço para análise da racionalidade, dos desejos e 
das capacidades adjacentes à ação. Nessa perspectiva, não existe apenas uma ação possível, um tipo de racionalidade, mas um conjunto de racionalidades explicativas das ações.

No caso do assentamento Conquista da Esperança, localizado no Município de Tupanciretã-RS, questões como as origens culturais das famílias, seu vínculo com o Movimento dos Trabalhadores Sem TerraMST, as características da UPA (área, solo), da família (número de pessoas, força de trabalho disponível, idades, escolaridades) e do território (organizações locais, mercados, etc) são elementos que podem influenciar a agência das famílias e devem ser investigados.

Todavia, Long e Ploeg (1994) alertam que, embora esses fatores influenciem, não é possível afirmar que definam ou determinem a agência das famílias. Como se pode observar, a noção de agência humana (ou da capacidade e/ou possibilidade de agir) é um conceito central na POA porque "atribui ao ator individual a capacidade de processar a experiência social e desenhar maneiras de lidar com a vida [...] os atores sociais possuem capacidade de saber e capacidade de atuar" (LONG, 2007, p.48).

Entretanto, Niederle (2007) lembra que, apesar da POA se dedicar às estratégias, relações e representações sociais dos atores, deve-se reconhecer também a importância da influência das estruturas sobre os atores. Considerando a discussão proposta, a POA permite analisar o comportamento dos atores sem presumir suas ações a partir dos estímulos do Estado, do agronegócio ou das orientações do MST, mas, ao mesmo tempo, reconhecendo sua influência.

Nesse contexto, a área de estudo desta pesquisa, compreende o Município de Tupanciretã, que contabilizou, em 2010, 22.281 habitantes, o que resultou em uma densidade demográfica de 9,89 habitantes por $\mathrm{km}^{2}$ (IBGE). Segundo dados do Instituto Brasileiro de Geografia e Estatistica, em 2010, 19,12\% dos habitantes viviam no meio rural, representando uma população de 4.261 pessoas. Dessa forma, percebe-se a representatividade dos assentamentos na população rural no município num contexto em que existem 649 famílias assentadas. Contudo, apesar de representar a maior parte da população rural, os assentamentos ocupam apenas $6 \%$ da área de Tupanciretã (COPTEC, 2010), sendo o restante ocupado por grandes fazendas que homogenizam a paisagem do município. O assentamento Conquista da 
Esperança foi criado em 1998 e é composto por 14 famílias que passaram por três acampamentos (Viamão, Julio de Castilhos e Tupanciretã) antes de serem assentadas (COPTEC, 2010).

Como as famílias assentadas estruturam seus sistemas produtivos nesse cenário de disputa entre a diversidade e a homogenização é o problema de pesquisa que se busca elucidar a partir das seguintes perguntas norteadoras: Quais são as estratégias de reprodução social adotadas pelas famílias assentadas? Quais são os estilos de agricultura presentes no assentamento? Quais as mudanças de estratégia podem ser percebidas nesse intervalo de tempo?

Entendendo-se o processo em curso, espera-se, com este estudo de caso, contribuir com uma análise das estratégias de reprodução social adotadas por famílias assentadas no assentamento Conquista da Esperança em Tupanciretã-RS, apontando os estilos de agricultura resultantes dessas diferentes estratégias. Além dessa compreensão acadêmica, espera-se contribuir com o trabalho da equipe técnica que atua no assentamento, produzindo um conjunto de informações sobre a influência da soja nas estratégias reprodutivas das famílias, bem como sobre os demais caminhos trilhados pelas mesmas no seu dia a dia.

\section{Procedimentos metodológicos}

Como instrumentos de investigação deste artigo, tem-se uma breve revisão bibliográfica no que tange aos conceitos desta temática e da problemática da pesquisa. Também se explora a pesquisa documental, a investigação com preenchimento de formulário/entrevista pré-estabelecida (ano 2013) e a consulta ao SIGRA da ATES para o ano de 2015

Esta pesquisa apropria-se da categoria de caráter explicativo, na qual Gil (2002 p. 16) afirma que as explicativas:

são aquelas pesquisas que tem como preocupação central identificar os fatores que determinam ou que contribuem para a ocorrência dos fenômenos. Este é o tipo de pesquisa que mais aprofunda o conhecimento da realidade, por que explica a razão, o porquê das coisas. 
Dessa maneira, para uma melhor compreensão, primeiramente foi realizada a parte empírica. Nessa parte, os procedimentos adotados dizem respeito à escolha da população e cálculo da amostra. Ressaltase que esta pesquisa tem caráter exploratório e explicativo, definindose como quantitativa e do tipo survey.

Num primeiro momento, definiu-se o tema, objetivos e problemática da pesquisa e, posteriormente, a população e amostra da mesma. A pesquisa foi censitária, ou seja, considerou toda a população do assentamento a 14 famílias.

No segundo momento, definiu-se a forma de coleta de dados, a qual compreendeu, para o ano de 2013, um formulário/entrevista estruturada, contendo 13 questões quantitativas e três qualitativas que, depois, foram agrupadas por similaridade da resposta. O formulário foi composto por dois blocos de questões. O primeiro referente à identificação do núcleo familiar com um universo de perguntas para definir os objetivos propostos e a origem das famílias, participação sociocultural das mesmas, entre outros fatores relevantes. O segundo bloco refere-se aos sistemas de produção das famílias, contendo perguntas exploratórias que identificassem a produção, volume de produção, tipo de produção e obervações gerais. Ressalta-se que se optou pelo aporte metodológico da entrevista/formulário ${ }^{2}$, pois segundo Gil (2002), a vantagem da entrevista perpassa algumas questões, como a obtenção de dados referentes aos mais diversos aspectos da vida social, sendo estes dados suscetíveis de classificação e de quantificação.

Foi realizada aplicação de formulário piloto para verificar a sua viabilidade. Em seguida, foram visitadas as 13 familias para coleta dos dados utilizados na análise. Uma família não pôde ser entrevistada porque, nas duas vezes em que foi realizado o trabalho de campo, não havia nenhum membro da família para responder ao formulário.

A análise desses dados ocorreu em três etapas. A primeira, compreendeu a estatística descritiva, que se resume na forma mais simples de análise dos dados e traz elementos, como cálculo de frequências, percentuais e cálculos de medidas dos atributos

2Gil (2002) também reporta as desvantagens da entrevista em relação aos questionários. Um exemplo é a desvantagem em relação a falta de motivação, muitas vezes do entrevistado, de responder às questões oua inadequada compreensão do significado das perguntas, entre outras limitações. 
considerados. A segunda etapa envolveu os cruzamentos, que têm por objetivo identificar quais variáveis podem ser cruzadas e analisadas para responder aos objetivos da pesquisa. Esses cruzamentos foram feitos a partir do programa SPSS (versão 20.0.0), o qual compreende um pacote estatístico para as ciências sociais, mas que pode ser utilizados para todas as áreas. É um programa que transforma os dados em informações estatisticamente comprovados e, a partir de cruzamentos estatísticos gera dados consistentes. A terceira etapa de análise dos dados 2013 consistiu na análise dos cruzamentos, os quais compõem os resultados e considerações iniciais do artigo.

O mesmo procedimento foi adotado para os dados do ano 2015, no entanto, o formulário foi substituído por consulta ao SIGRA. O SIGRA é um sistema informatizado, alimentado anualmente pelas equipes técnicas e que possui dados referentes a quem são, como vivem, como são os lotes, o que e como produzem as famílias assentadas no Rio Grande do Sul. Assim, os dados quantitativos referentes ao ano 2015 foram obtidos consultando o SIGRA.

\section{0 assentamento e a produção das famílias assentadas}

Nesta seção, serão apresentados e discutidos dados referentes à população e à produção do assentamento Consquista da Esperança. No âmbito da população, serão abordados a composição das famílias (origem da família, número de pessoas, idade e sexo), a escolaridade dos indivíduos e a composição da força de trabalho.

Em relação à produção, será realizada uma caracterização das atividades desenvolvidas pelas famílias, bem como uma discussão dos sistemas de produção resultantes de suas combinações em cada lote. Ao final, os sistemas de produção são discutidos à luz das estratégias de reprodução da agricultura familiar e da realidade da agricultura da região do Município de Tupanciretã-RS.

\subsection{Caracterização geral da população}

Dentre as famílias investigadas no assentamento Conquista da Esperança (13 de 14 famílias), não foi observada uma variação significativa na população nos dois anos pesquisados, conforme 
demonstra a Figura I. Tem-se aproximadamente $30 \%$ da população do assentamento com até 15 anos, um quarto até os 30 anos, $40 \%$ da população entre 31 e 54 anos e também aproximadamente, 5\% da população com mais de 55 anos.. Cabe destacar que, nesse período duas famílias mudaram do assentamento e um casal que residia junto com os pais também foi embora, de forma que a população total do assentamento reduziu de 64 para 61 pessoas. 
Figura 1. Faixas etárias econtradas no Assentamento Conquista da Esperança-Tupanciretã/RS nos anos 2013 e 2015

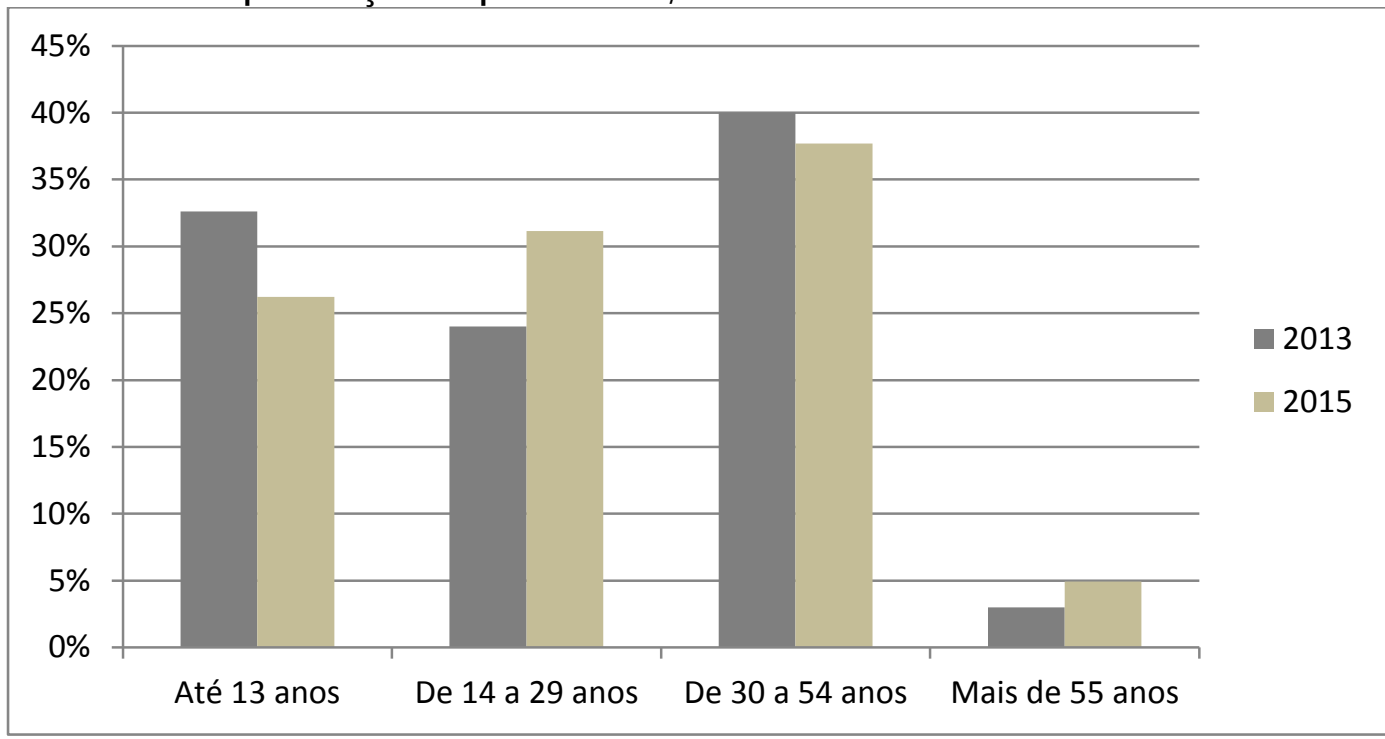

Fonte: Pesquisa de campo (2013) e SIGRA (2015).

Desses dados, depreende-se que, apesar do assentamento já possuir 16 anos, a idade de sua população ainda é jovem, pois aproximadamente $65 \%$ das pessoas estão em idade de trabalho e $25 \%$ possuem menos de 14 anos de idade, enquanto que menos de $5 \%$ possui mais de 55 anos. Essa realidade contrapõe-se a um conjunto de estudos sobre o processo de envelhecimento da população rural no âmbito da agricultura familiar (CAMARANO e ABRAMOVAY, 1999; ANJOS e CALDAS, 2005; FROEHLICH et al., 2011). No entanto, percebe-se que, de 2013 para 2015, ocorreu um incremento na média de idade geral do assentamento da ordem de $11,5 \%$ (passou de 25,7 para 28,6 anos) e, nos próximos anos, a questão do envelhecimento poderá ser se tornar uma questão relevante.

Em relação ao processo de masculinização, o assentamento se aproxima dos estudos acima citados, mas não permite conclusões afirmativas, pois, em 2013, 53,4\% dos indivíduos eram do sexo masculino, enquanto que $46,6 \%$ eram do sexo feminino. Já em 2015 , o percentual muda para $50,8 \%$ do sexo masculino e $49,2 \%$ do sexo feminino. Ao analisar-se a divisão por gênero e faixa etária, percebe-se um número maior de homens do que de mulheres na faixa dos 30 aos 54 anos, enquanto que existe uma pequena superioridade feminina na faixa etária até os 14 anos, denotando que pode existir um processo 
mais consistente de saída de jovens do sexo feminino do assentamento, o que corrobora os estudos sobre o tema acima citados.

Em relação à escolaridade, tem-se que pouco mais de $70 \%$ dos habitantes possui ensino fundamental incompleto (sendo maior no sexo masculino), aproximadamente $5 \%$ possui o ensino fundamental completo, $12 \%$ possui médio incompleto (sem diferença entre os sexos) e, aproximadamente 4\%, possuem ensino médio completo (sendo os 2 casos encontrados do sexo feminino). Existem ainda $2 \%$ de analfabetos e $5 \%$ ainda não escolarizados. Nesse sentido, a realidade do assentamento reafirma o já encontrado na realidade da agricultura familiar em que a escolaridade do sexo feminino é maior do que no sexo masculino. Analisando-se os anos de estudo em relação à idade, identifica-se uma correlação positiva entre mais anos de estudo e a faixa etária entre os 14 e 29 anos.

Em relação ao número de pessoas por família, a Figura 2 mostra que o assentamento é composto por $15,4 \%$ das famílias com duas pessoas, $23,1 \%$, com três pessoas, $23,1 \%$, com quatro pessoas, $7,7 \%$, com cinco pessoas, $23,1 \%$ com seis pessoas e $7,7 \%$ com dez pessoas. Informação relevante é que não existem lotes no assentamento habitados por apenas uma pessoa, uma vez que todos são ocupados por famílias que possuem entre duas e sete pessoas, com uma média de 4,5 habitantes/lote e um desvio padrão de 2,2 habitantes.

Figura 2. Número de pessoas por família no Assentamento Conquista da Esperança-Tupanciretã-RS no ano de 2015

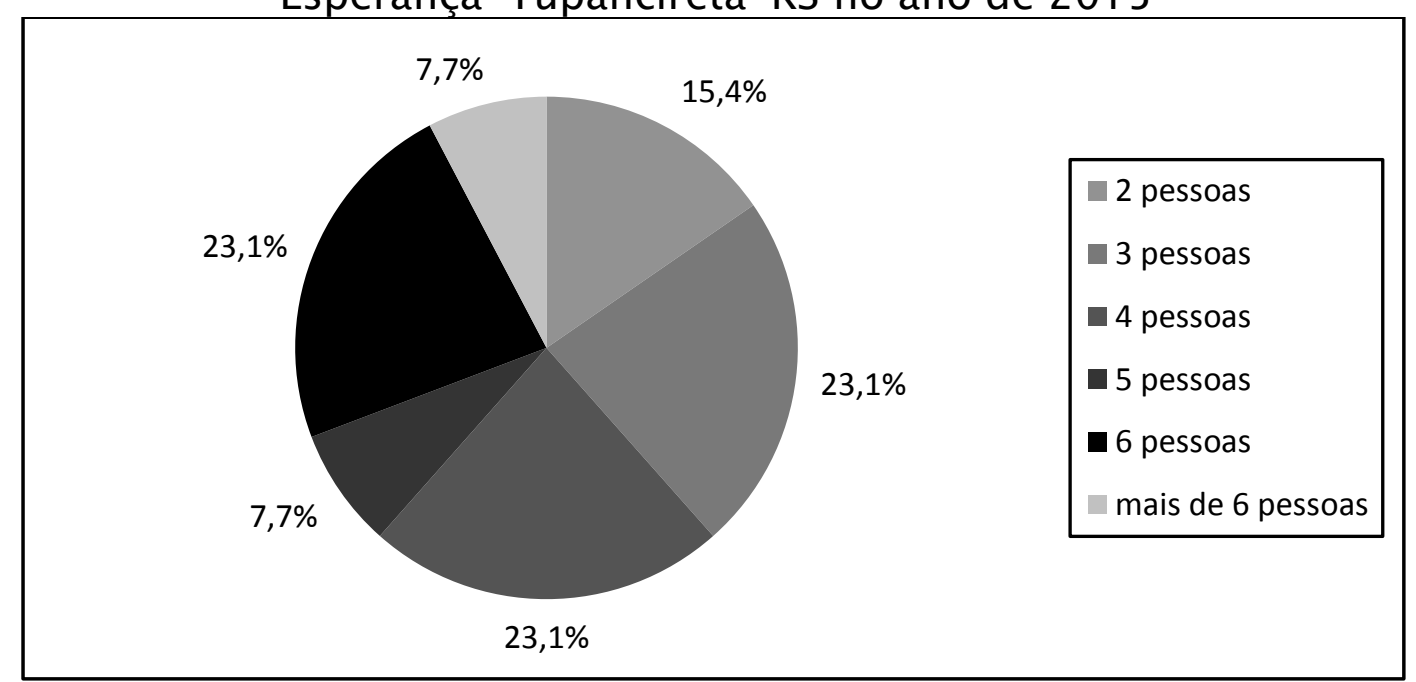

Fonte: SIGRA (2015). 
No entanto, o número de pessoas por família não significa exatamente força de trabalho disponível para o trabalho agrícola, pois, na família, estão inclusos crianças e idosos. Para representar a capacidade de trabalho disponível, é utilizado o conceito de Unidade de Trabalho Homem-UTH. No assentamento Conquista da Esperança, a UTH média é de 2,5, com mínimo de 1,0 UTH, máximo de 5,5 UTH e desvio padrão de 1,2 UTH (não houve mudança significativa entre os anos, mesmo com mudança de famílias e da idade dos indivíduos). Percebe-se que, em média, existem dois membros ativos em cada família e que a capacidade de trabalho é bastante variada, representada pelos valores máximo e mínimo de UTH, possibilitando a constituição de diferentes estratégias reprodutivas e estilos de agricultura.

No que tange à frequência da ocupação principal das famílias do assentamento, constatou-se que a maior frequência encontra-se na categoria agricultor, correspondendo a $50 \%$. Os estudantes representam a segunda parcela mais significativa $35 \%$ sendo que categorias como empregada doméstica, trabalhador da construção civil, empregado agrícola, nenhuma ocupação (nesse caso, crianças) e aposentadorias perfazem os demais. Dessa maneira, tem-se a agricultura como a principal estratégia de reprodução sociofamiliar no assentamento em estudo.

$\mathrm{Na}$ análise da variável outra ocupação em relação ao sexo, observa-se que a realidade do assentamento confirma os dados referentes à ocupação principal em relação ao gênero e está análoga ao que se apresenta historicamente na sociedade em relação a diferenciação de trabalho por gênero. Percebe-se claramente que as ocupações tidas como masculinas ao longo da história se reproduzem também nesses dados, em que a construção civil, assalariado do comércio e prestação de serviços encontram-se distribuídas em maior número na categoria do sexo masculino, enquanto o traballho doméstico é desempenhado por mulheres

No que tange à análise da origem das famílias do assentamento, cada uma delas é oriunda de um município diferente do Estado do Rio Grande do Sul. Nesse sentido, observou-se, por meio da análise dos dados, que a origem das famílias não foi o fator determinante para as estratégias atuais da agricultura familiar do assentamento. Dois fatores são essenciais para essa análise sendo as condições geográficas e 
adaptação às condições de produção já existentes. A origem da maioria das famílias é o norte do estado, o que dessa forma não diferencia em grandes proporções da região central do estado. O segundo fator é que, na maioria dos casos, as famílias tendem a se adaptar à produção agrícola que é realizada no espaço onde se instalam.

Outro elemento observado é que nenhum lote é utilizado apenas como moradia, pois quem desempenha alguma atividade secundária dedica apenas metade do tempo e quando há dedicação integral, o cônjuge fica no lote para exercer as atividades da UPA. Da mesma forma, infere-se que a grande maioria dos informantes tem origem rural antes de serem assentadas, pois, ao responderem o formulário em 2013, das 13 famílias analisadas, 12 declararam origem rural, totalizando um percentual de $92,3 \%$ da população. O mesmo pode ser afirmado em relação ao tempo em que estão assentadas - 53,8\% das famílias estavam há 14 anos assentadas-, isto é, desde a criação do assentamento. $O$ tempo de assentados das famílias restantes varia entre 4 e 12 anos, totalizando uma média de 11 anos para o conjunto das famílias, dado modificado, em 2015, com o ingresso de duas novas famílias no assentamento.

Quanto ao percentual de beneficiários do Bolsa Família, nota-se que $46,2 \%$ das famílias recebiam esse benefício em 2013 , dado que não se alterou em 2015. Contudo, ao contrário do que era esperado, os beneficiários com maior tempo assentado são os que apresentam maior frequência. Em contrapartida, os assentados mais recentes não vêm recebendo o benefício. Além disso, pode-se afirmar que as famílias que possuem menor mão de obra agrícola disponível para o trabalho são beneficiárias dos programas sociais, sendo que, à medida que esta unidade aumenta, deixa de ser um fator explicativo.

\subsection{Caracterização geral das atividades}

Verifica-se na Figura 3 a diversidade de atividades que são desenvolvidas pelas famílias no assentamento Conquista da Esperança em 2013. Dentre as atividades agrícolas predominantes, destacam-se a bovinocultura de leite, o cultivo da soja e a suinocultura. Destaca-se as múltiplas atividades nas UPA que, em muitos casos, são complementares aos sistemas de produção adotados. Dessa forma, as 
diferentes combinações dessas atividades são partes dos diversos sistemas produtivos apresentados e discutidos no item 2.3.

Figura 3. Diversidade de atividades desenvolvidas no Assentamento Conquista da Esperança-Tupanciretã/RS em 2013

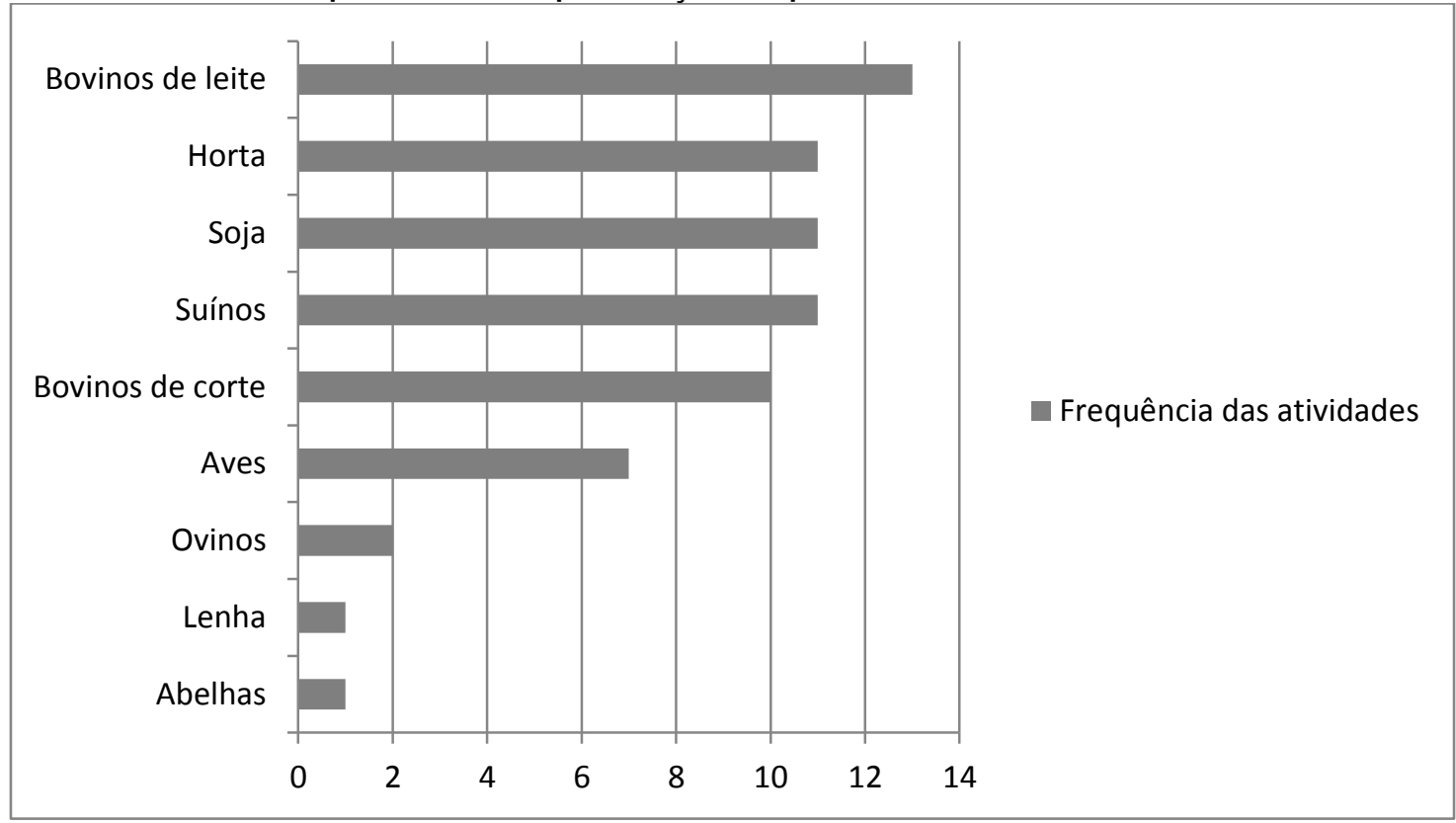

Fonte: Pesquisa de campo (2013)

Em 2015 percebe-se a manutenção da diversidade de cultivos e criações, no entanto, existe uma maior concentração das atividades de cunho comercial nas atividades leiteira, na horta e na soja e uma consequente redução na bovinocultura de corte, na avicultura e na lenha.

\subsubsection{A cultura da soja}

A cultura da soja estava presente nas estratégias de 11 famílias do assentamento em 2013, totalizando uma área de cultivo de 172,5 ha, ao passo que compõe o universo de 11 famílias e 122 ha em 2015 (ver a Tabela 1). Nesse período, a família que cultivava a maior área (90 ha) reduziu a área para 37 ha intensificando a produção leiteira. Outras duas famílias deixaram o cultivo dedicando-se também à atividade leiteira. Por outro lado, duas famílias ingressaram na atividade: uma que está há pouco tempo no assentamento e a outra, que chegou recentemente, aumentou significativamente a área plantada no lote 
quando comparado com o ano de 2013 e a família anterior. As demais famílias mantiveram as mesmas áreas cultivadas.

Em 2013, havia grande diferença entre as áreas cultivadas, culminando num alto desvio padrão (24,7 ha). O mesmo é verificado na produção, onde foram produzidos 5.964 sacas. Outro aspecto a ressaltar é em relação à produtividade da soja, que correspondeu a $2.074 \mathrm{~kg} / \mathrm{ha}$ (ou a $34,6 \mathrm{sc} / \mathrm{ha}$ ), uma produtividade considerada baixa porque a safra 2012 sofreu com secas na região. No entanto, ainda assim, a produtividade da soja no assentamento, segundo dados da Fundação de Economia e Estatistica-FEE (2013), esteve acima da média do município. Os mesmos dados apontam que a produtividade também foi maior que a do Estado do Rio Grande do Sul para o ano de 2012, que obteve uma produtividade $1430 \mathrm{~kg} / \mathrm{ha}$.

Já em 2015, o desvio padrão no tamanho das áreas foi menor, sendo a maior área de 37 ha e a menor de três ha, mas a média foi de dez ha. Nos 122 ha cultivados, foram colhidas 4.433 sacas, uma média de $2.180 \mathrm{~kg} / \mathrm{ha}(36,33 \mathrm{sc} / \mathrm{ha})$. A média municipal foi de 45,24 sc/ha e a estadual de 43,59 sc/ha (FEE, 2016).

Tabela 1. Caracterização da produção de soja do Assentamento Conquista da Esperança, Tupanciretã-RS nas safras 2012 e 2014

\begin{tabular}{c|c|c|c|c|c|c|c|c}
\hline & \multicolumn{4}{|c|}{ Área (ha) } & \multicolumn{4}{c}{ Produção $(\mathrm{kg})$} \\
\hline Ano & Total & Menor & Maior & Média & Total & Menor & Maior & Média \\
\hline 2012 & 172,5 & 5,0 & 90,0 & 15,7 & 357.840 & 7.800 & 216.000 & 32.531 \\
\hline 2014 & 122,0 & 3,0 & 37,0 & 11,1 & 266.000 & 7.000 & 85.800 & 24.180 \\
\hline
\end{tabular}

Fonte: Pesquisa de campo (2013) e SIGRA (2015).

\subsubsection{Atividade leiteira}

A atividade leiteira envolvia todas as famílias do assentamento em 2013, totalizando, como mostra a Tabela 2, um rebanho de 127 animais em período de lactação, que produziram no ano mais de 460 mil litros de leite. $\mathrm{O}$ maior rebanho era de 22 cabeças, enquanto que o menor era de somente 2 cabeças, com média de 9,8 cabeças/família (dado representativo da maioria dos produtores). Destaca-se que a família que detém o menor rebanho -2 cabeças-, é a exceção no que se refere à comercialização, realizando a venda do leite diretamente em domićlio na sede do Município de Tupanciretã. As demais famílias 
comercializavam a produção diretamente nas cooperativas da região, que entregavam o leite para o beneficiamento na indústria.

Em 2015, houve um pequeno incremento do rebanho que passou a perfazer um total de 140 animais que produziram quase 507 mil litros de leite. O maior rebanho passou para 51 animais (do produtor que diminuiu a grande área de soja e intensificou a produção leiteira) e o menor foi de 3 animais, sendo a média de 10,8 animais/família (dado representativo da maioria dos produtores).

Tabela 2. Caracterização da atividade leiteira do Assentamento Conquista da Esperança, Tupanciretã-RS - nas safras 2012 e 2014

\begin{tabular}{c|c|c|c|c|c|c|c|c|}
\hline & \multicolumn{4}{|c|}{ Rebanho (cabeças) } & \multicolumn{4}{c}{ Produção (litros) } \\
\hline & Total & Menor & Maior & Média & Total & Menor & Maior & Média \\
\hline 2012 & 127 & 2 & 22 & 9,8 & 460.224 & 4.500 & 144.000 & 35.402 \\
\hline 2014 & 140 & 3 & 51 & 10,8 & 506.787 & 4.200 & 203.607 & 38.983 \\
\hline
\end{tabular}

Fonte: Pesquisa de campo (2013) e SIGRA (2015).

Em relação às tecnologias utilizadas na produção leiteira, em 2013,84,6\% das famílias utilizam a ordenhadeira mecânica, enquanto que $15,4 \%$ corresponde à duas famílias que o fazem de forma manual. $O$ armazenamento é realizado nas propriedades por meio de resfriadores a granel, utilizado por $53,8 \%$ das famílias, em sistema de tarros, por $38,5 \%$, sendo que os $7,7 \%$ restantes, acondicionam a produção em refrigerador doméstico, uma vez que esta é menor e a venda ocorre diretamente em domicílio. 
Destaca-se que a produtividade e a produção podem oscilar muito conforme a quantidade de animais em lactação em cada família e também durante os diferentes períodos do ano, uma vez que estão suscetíveis às condições da natureza, como temperatura, pluviosidade, estações do ano, oferta forrageira, período reprodutivo do rebanho, etc. No entanto, a produtividade média, em 2013, foi de 3.623 litros/vaca/ano. Essa produtividade está abaixo da média de produtividade do município, conforme dados da FEE (2013), pois no ano de 2010 a produtividade já era de 4.050 litros/vaca/ano.

No ano de 2015 , tem-se o mesmo desenho tecnológico para a produção leiteira do assentamento, o que acarretou em manutenção da produtividade que alcançou 3.620 litros/vaca/ano. No entanto, houve um incremento de rebanho como mostrado na Tabela 2 , o que aumentou a produção total e tornou a atividade leiteira mais importante.

\subsubsection{Atividade não agrícola}

Observou-se que, em 2013, as atividades não agrícolas estavam presentes em $77 \%$ das famílias, indicando, nesses casos, que pelo menos um membro da família desempenhava alguma atividade de trabalho não agrícola. A proximidade do assentamento da sede do município $(3 \mathrm{~km}$ ) contribui para a expressividade do trabalho não agrícola. Dentre as atividades, destacaram-se aquelas exercidas na construção civil (que permitiam o trabalho agrícola em tempo parcial), doméstica, mecânica e serralheria (que ocupavam 100\% da dedicação dos indivíduos).

Em 2015, a construção civil perdeu trabalhadores que se voltaram para a atividade agrícola como ocupação principal, mas mantiveram o trabalho não agrícola como ocupação secundária.

\subsubsection{Autoconsumo}

O autoconsumo foi caracterizado a partir da ocorrência de alimentos na UPA, sendo categorizado em relação ao número de itens disponíveis na unidade de produção. As categorias foram construídas conforme a origem dos alimentos em animal, vegetal e processados. Nota-se que, independente da quantidade produzida, e para os dois 
anos, todas as famílias produzem alimentos para o autoconsumo o que reflete suas características culturais e econômicas. Verificou-se a existência de uma diversidade de itens produzidos, sejam eles de origem animal, vegetal e processados ${ }^{3}$. Em 2013 apenas uma família apresentou quantidade menor a dez itens para o autoconsumo, número que passou para duas com a família nova do assentamento. Outras seis famílias apresentaram entre 10 e 20 itens, número mantido em 2015 e seis em 2013 e cinco em 2015 , respectivamente, produziam mais de 20 itens destinados ao autoconsumo.

${ }^{3}$ Dentre os produtos de origem vegetal, destacam-se a alface, repolho, cenoura, beterraba, rabanete, pimenta, milho verde, rúcula, abóbora, morango, etc. Nos produtos de origem animal aparecem as carnes suína, bovina, ovina, avícola, ovos, etc. Em relação aos produtos processados, destacam-se os sucos, vinho, salames, doces, biscoitos, queijos, pães, etc. 
Ressalta-se que a pesquisa de campos identificou que as famílias onde a produção de itens é maior está relacionada a ocorrência de comercialização destes produtos e também verificou-se a maior utilização desses alimentos para o consumo das famílias.

\subsubsection{Outras atividades}

Em 2013, além das atividades mais representativas como o binômio soja-leite, destacam-se outras atividades, entre elas a exploração florestal, a produção de ovos, a bovinocultura de corte, a ovinocultura, apicultura e suinocultura.

A atividade de exploração florestal é realizada por meio do cultivo de eucalipto para comercialização de lenha que é realizada na sede do município. Assim, verificou-se que essa atividade é complementar às demais. Outra atividade complementar desenvolvida por duas famílias é a avicultura de postura para comercialização de ovos. A bovinocultura de corte também aparece como atividade complementar de duas famílias no assentamento, percebendo-se uma diversidade de atividades desenvolvidas pelas famílias, as quais vão muito além do binônimo soja-leite que são produções características da região.

Em 2015, percebeu-se uma intensificação da produção de soja e leite como o respectivo abandono de algumas atividades, como a florestal, a bovinocultura de corte e a produção de ovos. Outra atividade que foi intensificada no assentamento foi a horticultura comercial, que já era praticada por algumas famílias em 2013, mas foi intensificada, em 2015, em função da comercialização para o Programa Nacional de Alimentação Escolar-PNAE e do incentivo e apoio da assessoria técnica prestada pela Cooperativa de Prestação de Serviços Técnicos-COPTEC.

\subsection{Discussão dos sistemas de produção}

A caracterização dos sistemas produtivos foi realizada com base nas informações fornecidas pelas famílias sobre as atividades produtivas desempenhadas no lote e/ou fora para o ano de 2012 e coletadas no SIGRA para o ano de 2014. O Quadro 1 apresenta uma síntese dos sistemas produtivos encontrados no assentamento em 2013 e em 2014, ordenados por repetição. 
Tabela 5. Sistemas Produtivos encontrados no Assentamento Conquista da Esperança, Tupanciretã-RS nos anos 2012 e 2104

\begin{tabular}{|c|c|c|c|}
\hline UPA & 2012 & 2014 & Variação \\
\hline 1 & $\begin{array}{l}\text { Leite / Soja / } \\
\text { Trabalho não agrícola }\end{array}$ & $\begin{array}{l}\text { Leite / Soja / } \\
\text { Trabalho não agrícola }\end{array}$ & Sem mudanças \\
\hline 2 & $\begin{array}{l}\text { Leite / Soja / } \\
\text { Trabalho não agrícola }\end{array}$ & $\begin{array}{l}\text { Leite / Trabalho não } \\
\text { agrícola }\end{array}$ & Parou de cultivar soja \\
\hline 3 & $\begin{array}{l}\text { Leite / Soja / } \\
\text { Trabalho não agrícola }\end{array}$ & Leite / Soja / Horta & $\begin{array}{l}\text { Substituiu o trabalho fora do lote } \\
\text { pela horta }\end{array}$ \\
\hline 4 & $\begin{array}{l}\text { Leite / Soja / } \\
\text { Trabalho não agrícola }\end{array}$ & $\begin{array}{l}\text { Leite / Trabalho não } \\
\text { agrícola }\end{array}$ & $\begin{array}{l}\text { Parou de cultivar soja, diminuiu } \\
\text { toda a prodçução porque filha e } \\
\text { genro saíram do lote }\end{array}$ \\
\hline 5 & Leite / Soja & Leite / Soja & $\begin{array}{l}\text { Aumentou o leite e diminuiu o } \\
\text { cultivo de soja }\end{array}$ \\
\hline 6 & Leite / Soja & $\begin{array}{l}\text { Leite / Soja / } \\
\text { Trabalho não agrícola }\end{array}$ & $\begin{array}{l}\text { O ingresso de } 1 \text { UTH foi } \\
\text { destinado ao trabalho não } \\
\text { agrícola }\end{array}$ \\
\hline 7 & $\begin{array}{l}\text { Leite / Soja / gado de } \\
\text { Corte }\end{array}$ & Leite / Soja & $\begin{array}{l}\text { Terminou com gado de corte e } \\
\text { aumentou área cultivada de soja }\end{array}$ \\
\hline 8 & $\begin{array}{l}\text { Soja / Horta / Gado } \\
\text { corte }\end{array}$ & Soja / Horta & $\begin{array}{l}\text { Gado de corte apenas para } \\
\text { consumo, incrementou a horta e } \\
\text { está iniciando na atividade leiteira }\end{array}$ \\
\hline 9 & Leite / Soja / Horta & Leite / Soja / Horta & $\begin{array}{l}\text { Manteve a área cultivada com } \\
\text { soja, reduziu a produção de leite } \\
\text { e aumentou a dedicação à horta }\end{array}$ \\
\hline 10 & Leite / Soja / Ovos & $\begin{array}{l}\text { Leite / Soja / } \\
\text { Trabalho não agrícola }\end{array}$ & $\begin{array}{l}\text { Trocou a produção de ovos pela } \\
\text { atividade não agrícola }\end{array}$ \\
\hline 11 & Leite / Soja / Lenha & $\begin{array}{l}\text { Leite / Soja / Gado de } \\
\text { Corte }\end{array}$ & $\begin{array}{l}\text { Mudou a família. Mantém o leite, } \\
\text { mas entrou a pecuária de corte e } \\
\text { aumentou o cultivo da soja }\end{array}$ \\
\hline 12 & Leite / Ovos & Leite / Soja & Ingressou no cultivo de soja \\
\hline 13 & $\begin{array}{l}\text { Leite / Trabalho não- } \\
\text { agrícola }\end{array}$ & $\begin{array}{l}\text { Soja / Trabalho não- } \\
\text { agrícola }\end{array}$ & $\begin{array}{l}\text { Família que chegou ao } \\
\text { assentamento e optou por } \\
\text { atividades que não demandam } \\
\text { infraestrutura própria (para } \\
\text { cultivo da soja pode contratar o } \\
\text { maquinário) }\end{array}$ \\
\hline
\end{tabular}

Fonte: Pesquisa de campo (2013) e SIGRA (2015)

Percebe-se, que em 2013, o binômio soja/leite está presente em 77\% das UPAs do assentamento, reproduzindo, em parte, a estrutura produtiva regional. No entanto, é fundamental perceber que na maioria das UPAs esse binômio se articulava e era complementado por uma terceira atividade (trabalho não agrícola, gado corte, lenha, horta, ovos), configurando diferentes estilos de agricultura no interior do assentamento. Além disso, ressalta-se, em face da dimensão do cultivo 
de soja no entorno do assentamento e da expectativa de seu predomínio no assentamento, além da diversidade já apontada, a presença de duas UPAs que não cultivavam o grão.

Em 2015, mantém-se o amplo predomínio da soja e do leite, mas com uma redução do binômio (duas UPAs param com a soja e se especializam no leite), e ocorre uma redução das atividades diversificadas (lenha, ovos, etc) e uma concentração/especialização no leite e na soja aliados ao reforço no trabalho não agrícola eventual e na horticultura, essa estimulada pelas compras institucionais.

O autoconsumo, originado de fatores econômicos (redução do custo da alimentação) ou culturais, não foi considerado como um elemento definidor dos sistemas de produção porque está presente, em diferentes graus, em todas as UPAs, pois as mesmas apresentam diferentes sistemas produtivos com viés econômico e a produção para o autoconsumo como mais um elemento de diversificação e composição de suas estratégias de reprodução.

Independentemente das combinações, o que se percebe é que as famílias assentadas manejam suas atividades produtivas de acordo com a disponibilidade de força de trabalho, de recursos financeiros, da variação de preços e da existência de políticas de apoio à produção e à comercialização.

Ao buscar correlações com outros elementos para explicar a escolha por determinado estilo de agricultura, não foi encontrada correlação positiva entre os sistemas produtivos e a UTH das famílias, nem com o recebimento do Bolsa Família, tempo de assentamento ou com a origem das famílias.

Questionados sobre quais são suas expectativas e estratégias para o futuro, as respostas, em 2013, foram unânimes, indicando a intenção de redução da área destinada ao cultivo da soja e o incremento da produção leiteira. Os principais argumentou mobilizados referem-se a três fatores, em ordem crescente de importância: 1. O leite gera uma renda mensal à família enquanto que a soja possibilita apenas um ingresso anual; 2. O leite gera uma renda maior ao longo do ano; e, 3. O risco da atividade leiteira é menor.

Passados dois anos, identifica-se que essa transição para a atividade leiteira não ocorreu massivamente. Alguns fatores podem fornecer pistas sobre os motivos para a manutenção (e em alguns casos 
ampliação) da área destinada à soja no assentamento. Um deles é a atratividade do preço da soja, que alcançou, em 2014, e manteve, em 2015 e 2016, preços muito elevados. Outro fator são as garantias de compra (especialmente se considerada a crise do setor leiteiro), além da reduzida necessidade de força de trabalho que pesa contra a atividade leiteira e a horticultura, outra alternativa que está em estruturação.

Considerados esses elementos, o rearranjo futuro dos sistemas de produção a partir do incremento da atividade leiteira, da soja ou de outras iniciativas merece um acompanhamento e nova problematização.

\section{Conclusões}

Conclui-se que, em que pese a pressão exercida pelo agronegócio nos assentamentos, em especial pelo entorno do assentamento Conquista da Esperança, as famílias assentadas confirmam a tendência da agricultura familiar de desenvolver respostas individuais e configurar uma diversidade de estratégias reprodutivas e de estilos de agricultura no assentamento diferindo do estilo de agricultura predominante no município oriundo da agricultura patronal e caracterizado pelo cultivo isolado de soja.

A diversidade de estilos de agricultura presente no assentamento baseia-se principalmente no binômio soja-leite, mas é incrementada em todas as UPAs com uma terceira ocupação, sendo mais representativa sa ocupação, não agrícola, a horticultura e a bovinocultura de corte.

Conclui-se que essa diversidade de estratégias reprodutivas e de estilos de agricultura é reflexo do dinamismo social e econômico em que o assentamento está inserido. Dinamismo este, resultado da sua proximidade com o centro urbano, da existência de uma diversidade de estruturas produtivas que the permite escolhas (ex.: existem três empresas com rota de leite dentro do assentamento), de uma organização local das próprias famílias assentadas que se apresenta como alternativa e que dá suporte e apoio às famílias (Coperterra) e á orientação e estímulo visando a produção de alimentos e a agroecologia oferecida pela Coptec via ATES para as famílias assentadas.

A pluriatividade, nos moldes presenciados, pode ser reflexo da proximidade com um centro urbano, o que facilita o trabalho em tempo 
parcial, assim como facilita a comercialização direta da produção agrícola do assentamento.

Uma questão de pesquisa para o futuro é compreender se nos assentamentos distantes de centros urbanos a pluriatividade também é tão presente e quais são suas características, traçando um estudo comparativo entre essas duas realidades.

Outra questão para pesquisas posteriores refere-se ao futuro da juventude do assentamento. Em que pese a presença dos jovens no assentamento ainda ser marcante e o envelhecimento ainda não ser um problema, o futuro que esses jovens escolherão definirá o futuro do assentamento. Existe a real possibilidade dos jovens do assentamento optarem pela saída da atividade agrícola, acompanhando o movimento geral da juventude da agricultura familiar. Pensando nessa possibilidade, é míster o Instituto Nacional de Colonização e Reforma Agrária (INCRA) e as demais organizações envolvidas com a reforma agrária discutirem esse processo.

\section{REFERÊNCIAS}

ANJOS, F.S.; CALDAS, N.V. O futuro ameaçado: o mundo rural face aos desafios da masculinização, do envelhecimento e da desagrarização. Ensaios FEE, Porto Alegre, v.26, n.1, p.661-694, 2005.

CAMARANO, A.A.; ABRAMOVAY, R. Exxodo rural, envelhecimento e masculinização no Brasil: panorama dos últimos 50 anos. Rio de Janeiro: IPEA, $1999.28 \mathrm{p}$. Disponível em: <http://www.dominiopublico.gov.br/download/texto/td_0621.pdf >. Acesso em: dez. 2013.

CARNEIRO, M. S. Práticas, discursos e arenas: Notas sobre a socioantropologia do desenvolvimento. Rio de Janeiro: Revista Sociologia \& Antropologia, v. 02.04, p. 129-158, 2012.

CERDAN, C. Valorização dos produtos de origem e do patrimônio dos territórios rurais no sul do Brasil: Contribuição para o desenvolvimento territorial sustentável. Política \& Sociedade, v.8, n.14, p. 277-299, 2009. Disponível

em: 
<http://www.periodicos.ufsc.br/index.php/politica/article/viewFile/ 116 26/10961 >. Acesso em: jan./2014.

CONTERATO, M.A. A mercantilização da agricultura familiar no Alto Uruguai/RS: um estudo de caso no município de Três Palmeiras. 2004. 209 p. Dissertação (Mestrado em Desenvolvimento Rural), Programa de Pós-graduação em Desenvolvimento Rural, Universidade Federal do Rio Grande do Sul, Porto Alegre, 2004.

CONTERATO, M. A. Dinâmicas regionais do desenvolvimento rural e estilos de agricultura familiar: uma análise a partir do Rio Grande do Sul. 2008. 290 p. Tese (Doutorado em Desenvolvimento Rural), Programa de Pós-graduação em Desenvolvimento Rural, Universidade Federal do Rio Grande do Sul, Porto Alegre, 2008.

CONTERATO, M. A.; SCHNEIDER, S.; WAQUIL, P. D.Estilos de agricultura: Uma perspectiva para a análise da diversidade da agricultura familiar.Porto Alegre: Ensaios FEE, v. 31, n. 1, p. 149-186, 2010.

CONTERATO, M. A.; et al. Mercantilização e mercados: a construção da diversidade da agricultura na ruralidade contemporânea. In: SCHNEIDER, S.; GAZOLLA, M. (Org.). Os atores do desenvolvimento rural: perspectivas teóricas e práticas sociais. Porto Alegre: Editora da UFRGS, 2011, p. 67-89.

COPTEC - Cooperativa de Prestação de Serviços Técnicos. Plano de Recuperação do Assentamento Conquista da Esperança. 2010. Mimeo.

COTRIM, M. S. "Pecuária familiar" na região da "Serra do Sudeste" do Rio Grande do Sul: um estudo sobre a origem e a situação socioagroeconômica do pecuarista familiar no município de CanguçuRS. 2003. 142 p. Dissertação (Mestrado em Desenvolvimento Rural), Programa de Pós-graduação em Desenvolvimento Rural, Universidade Federal do Rio Grande do Sul, Porto Alegre, 2003.

COTRIM, D. S. Agroecologia, sustentabilidade $e$ os pescadores artesanais: O caso de Tramandaí-RS. 2008. 198 p. Dissertação 
(Mestrado em Desenvolvimento Rural), Programa de Pós-graduação em Desenvolvimento Rural, Universidade Federal do Rio Grande do Sul, Porto Alegre, 2008.

DEPONTI, C. M. Desmistificando a intervenção para o desenvolvimento à luz da Perspectiva Orientada ao Ator. Anais do VII Congresso da Sociedade Brasileira de Sistemas de Produção, Fortaleza, 2007, Disponível em: http://www.cnpat.embrapa.br/sbsp/anais/Trab_Format_PDF/19.pdf Acesso em: 03/08/2013.

FEE - Fundação de Economia e Estatística. FEE DADOS. Porto Alegre. 2016. Disponível em: <http://www.fee.rs.gov.br/feedados/>. Acesso em: 15 abr. 2016.

FEE - Fundação de Economia e Estatística. FEE DADOS. Porto Alegre. 2013. Disponível em: <http://www.fee.rs.gov.br/feedados/>. Acesso em: 10 dez. 2013.

FROEHLICH, J. M. et al. O "local" na atribuição de sentido ao desenvolvimento. Revista Paranaense de Desenvolvimento, Curitiba, n.94, p. 87-96, mai./dez. 1998.

FROEHLICH, J. M. et al. Êxodo seletivo, masculinização e envelhecimento da população rural na região central do RS. Ciência Rural, Santa Maria, v.41, n.9, p.1674-1680, set. 2011.

FROEHLICH, J. M. (org.). Desenvolvimento territorial: Produção, identidade e consumo.ljuí, Ed. Unijuí, 2011, 424p..

GAZOLLA, M. Agricultura familiar, segurança alimentar e políticas públicas: uma análise apartir da produção para autoconsumo no território do Alto Uruguai/RS. 2004. 287 p.Dissertação (Mestrado em Desenvolvimento Rural), Programa de Pós-graduação em Desenvolvimento Rural, Universidade Federal do Rio Grande do Sul, Porto Alegre, 2004. 
GIL, A. Métodos e técnicas de pesquisa social. São Paulo: Atlas, 4 ed., 2002.

IBGE. Censo Agropecuário 2006. Rio de Janeiro, IBGE, CD-ROM, 2009.

IPEA. Instituto de Pesquisa Econômica Aplicada. Disponível em: <www.ipeadata.gov.br>. Acesso em: 22 jul. 2009.

LONG, N. Sociología del desarrollo: uma perspectiva centrada em el actor. Colección Investigaciones. México: Centro de Investigaciones y Estudios Superiores em Antropologia Social, 2007.

LONG, N. e PLOEG, J. D. Heterogeneity, actor and structure: towards a reconstitution of theconcept of structure. In BOOTH, D. Rethinking Social Development. theory, researchand practice. England, Longman Scientific \& Technical, p. 62-90, 1994.

NIEDERLE, P. A. Mercantilização, estilos de agricultura e estratégias reprodutivas dos agricultores familiares de Salvador das Missões, RS. 2007. 218f. Dissertação (Mestrado em Desenvolvimento Rural), Programa de Pós-graduação em Desenvolvimento Rural, Universidade Federal do Rio Grande do Sul, Porto Alegre, 2007.

NIEDERLE, P. A. (org.). Indicações geográficas: Qualidade e origem nos mercados alimentares.Porto Alegre, Ed. UFRGS, 2013, 296p.

PECQUEUR, B. A guinada territorial da economia global.Política \& Sociedade, n. 14, p.79-105, abr. 2009.

PLOEG, J. D. van der. Styles of farming: an introductory note on concepts and methodology. In: PLOEG, J. D. van der; LONG, N. Born from within: practices and perspectives of endogenous rural development. Assen: Van Gorcum, 1994. p. 7-30.

SCHNEIDER, S. (org.). A diversidade da agricultura familiar. Porto Alegre, Ed. UFGRS, 2006, 296p. 
SCHNEIDER, S.Reflexões sobre diversidade e diversificação: agricultura, formas familiares e desenvolvimento rural. Ruris, v. 4, n. 1, p. 129-158, março 2010.

SCHNEIDER, S. e GAZOLLA, M. Os atores entram em cena. In: SCHNEIDER, S. e GAZOLLA, M. (org.). Os atores do desenvolvimento rural: Perspectivas teóricas e práticas sociais. Porto Alegre, UFGRS, 2011, p. 11-21.

SCHNEIDER, S.; NIEDERLE, P. A. Agricultura familiar e teoria social: a diversidade das formas familiares de produção na agricultura. In: Fábio Gelape Faleiro; Austeclinio Lopes de Farias Neto. (Org.). Savanas: Desafios e Estratégias para o Equilíbrio entre Sociedade, Agronegócio e Recursos Naturais. 1ed.Planaltina, DF: Embrapa Cerrados, p. 989-1014, 2008.

SIGRA. Sistema Integrado de Gestão Rural da ATES. 2015. Disponível em: $<$ http://www.sigra.net.br/>. Acesso em: 15 maio 2016.

Submetido em 30/05/2016

Aprovado em $21 / 08 / 2016$

Sobre os autores

Alisson Vicente Zarnott. Eng. Agrônomo, Doutorando do Programa de Pós-Graduação em Extensão Rural/UFSM.

E-mail: alissonae@yahoo.com.br

Eduardo Miotto Flech. Economista. Mestre em Extensão Rural/UFSM.

E-mail: eduardoflech000@yahoo.com.br

Pedro Selvino Neumann. Doutor, Professor Adjunta do Departamento de Extensão Agrícola e Extensão Rural/UFSM e do Programa de Pós-Graduação em Extensão Rural/UFSM.

E-mail: neumannsp@yahoo.com.br 